\title{
Postoperative management of Dupuytren's disease with topical nitroglycerin
}

\author{
Patrick I Emelife BA, Russell E Kling BA, Ronit Wollstein MD
}

PI Emelife, RE Kling, R Wollstein. Postoperative management of Dupuytren's disease with topical nitroglycerin. Can J Plast Surg 2012;20(4):249-250.

Dupuytren's contracture remains a significant clinical challenge due to associated complications and a recurrence rate of up to $60 \%$. Commonly, the operated skin tends to rebuild scar in the area of surgery. Assuming local ischemia as an etiological factor, two cases in which topical nitroglycerin was used following surgical treatment of Dupuytren's disease are presented. In these patients, no raised scar formation developed during healing. At least six months after surgery, disease recurrence was not noted and the patients and surgeon reported improved skin quality. In the present study, the use of topical nitroglycerin, a local vasodilator, appeared to prevent recurrent scar formation, possibly through prevention of local ischemia. Further study and follow-up is necessary.

Key Words: Dupuytren; Scar; Surgery; Topical nitroglycerin

$\mathrm{D}$ puytren's disease is a prevalent, incapacitating condition that affects up to $40 \%$ of the elderly population (1). Primarily affecting patient dexterity and function, the disease starts with palmar-skin fibroblast proliferation, accumulation of collagen around the aponeurosis, arrangement in nodules and later appearance of myofibroblasts that are responsible for finger contractures $(2,3)$.

Treatment consists of cord and nodule excision, with a relatively difficult recovery, a very high recurrence rate and less than perfect results (4-7). The reasons for the high rate of disease recurrence and recurrence of contracture and complications, such as complex regional pain syndrome, remain unknown. Recently, there has been a resurgence in percutaneous fasciotomy and the introduction of collagenase injections in an attempt to minimize complications $(8,9)$. The complication rate of these procedures remains under study, but recurrence remains an unresolved issue.

The authors believe that the etiology of the disease involves local ischemia resulting in scar that presents with an abnormal distribution. The high association of Dupuytren's disease with diabetes, alcoholism, smoking and anticonvulsant therapy in epilepsy supports this theory because these conditions often affect the peripheral nervous and vascular systems and can cause ischemic damage to the tissue (10-12). Local ischemia as a cause of Dupuytren's disease was proposed by Hueston (13) and, in some earlier studies of Dupuytren's disease, was the accepted etiology. Local ischemia was further investigated by Murrell $(14,15)$ based on the pattern of fibroblast proliferation. Madden et al (16) found that ischemic intrinsic muscle cells were similar to the myofibroblasts active in Dupuytren's contracture. Assuming this mechanism, topical nitroglycerin was used following Dupuytren's fasciectomy with the purpose of affecting immediate postoperative scar formation, and perhaps influencing the recurrence and scarring typically associated with surgery for Dupuytren's disease.

Topical nitroglycerin has been extensively described as an appropriate treatment modality for Raynaud's disease, scleroderma and other connective tissue disorders. These conditions are notably marked by an ischemic or vasospasmic pathophysiological mechanism (17). It has

\section{La prise en charge postopératoire de la maladie de Dupuytren par la nitroglycérine topique}

\begin{abstract}
La maladie de Dupuytren demeure un problème clinique important en raison des complications connexes et d'un taux de récurrence pouvant atteindre $60 \%$. La peau opérée a souvent tendance à former de nouvelles cicatrices. Les auteurs présentent deux cas pour lesquels ils ont utilisé de la nitroglycérine topique après le traitement chirurgical de la maladie de Dupuytren, selon l'hypothèse que l'ischémie locale représentait un facteur étiologique. Chez ces patients, aucune cicatrice surélevée ne s'est formée. Au moins six mois après l'opération, il n'y avait pas eu de récurrence de la maladie, et les patients et le chirurgien avaient fait état d'une meilleure qualité de la peau. Dans la présente étude, le recours à de la nitroglycérine topique, un vasodilatateur local, a semblé prévenir la formation de cicatrices récurrentes, peut-être en prévenant une ischémie locale. D’autres études et un suivi s'imposent.
\end{abstract}

also been used in the treatment of Achilles tendinitis and anal fissures $(18-20)$. Topical nitroglycerin is well tolerated and effective in these patients. We describe two patients who underwent surgical fasciectomy and were treated postoperatively with topical nitroglycerin. The cream was not used as part of a study.

\section{CASE PRESENTATIONS}

Case 1

A 66-year-old right-handed man with a medical history significant for diabetes mellitus type 2 treated with metformin presented with severe right Dupuytren's contracture of the ring and little fingers. The patient had smoked one pack per day for 20 years and had stopped smoking in 1987. He denied alcohol use since 1987 . His family history was positive for Dupuytren's disease. On examination, the metacarpophalangeal joint and proximal interphalangeal (PIP) joint were contracted in approximately $80^{\circ}$ and $90^{\circ}$ of flexion, respectively, in both involved fingers.

The patient underwent a standard (Dupuytren's) fasciectomy of the right ring finger, little finger and palm under axillary block anesthesia. Skin incisions included Brunner-type incisions and a V-Y plasty. In surgery, nearly the entire palm was noted to contain Dupuytren's tissue. This tissue was excised as optimally as possible, taking care to protect the neurovascular bundles. In the little finger, a very large, thick lateral/abductor cord was present, which was removed, as well as a nodule over P1. In the ring finger, a very large nodule over P1 was present. All of these were removed. The joints were straightened completely, although slight hyperextension remained in the distal interphalangeal joint of the little finger.

The patient's bulky dressing was removed at four days postsurgery and the fingers were splinted in extension. Nitropaste (topical nitroglycerin) was prescribed following suture removal at two weeks. It was prescribed to be used once per day at a dose of 1 inch applied to the affected site. At this time, the patient stopped wearing the splint during the day and commenced range of motion (ROM) exercises. Four weeks postsurgery, the patient lacked approximately $20^{\circ}$ of extension 
in the PIP joint of his little finger; however, he was able to form a nearly complete fist. The skin in the palm and fingers was soft and noted to be softer than expected after this type of surgery. The patient continued treatment with nitropaste. Three months after surgery, the patient's surgical incisions were 'excellent' and he had almost full ROM in the operated hand. At six months, there was no evidence of recurrence.

\section{Case 2}

A 61-year-old, right-handed man with a medical history significant for diabetes, seizure disorder and osteoarthritis was diagnosed with right ring trigger finger and a nodule in the area of the trigger finger of the A1 pulley. His medications included topiramate, glipizide and metformin. The patient denied smoking or drinking regularly, and had no family history of Dupuytren's contracture.

The patient underwent a Dupuytren's partial fasciectomy in the palm and an A1 pulley release of the right ring finger under local anesthesia. The surgery included a V-Y plasty, fasciectomy and release of the A1 pulley.

Following suture removal, daily topical nitroglycerin was applied. Seven weeks after surgery, the surgical wound was soft. The patient was prescribed night splinting for residual PIP joint contracture of $30^{\circ}$ flexion. At his 11-week follow up visit, the patient had full ROM in his right hand. This patient underwent a nine-month follow-up period with no evidence of recurrence.

\section{DISCUSSION}

Treatment of Dupuytren's disease remains a clinical challenge. Following surgery, the most important goal is to achieve maximal hand function. This is usually accomplished with splinting, hand therapy and rehabilitation. Because the patients have a tendency to heal with raised, hard, Dupuytren-like scars, secondary goals include softening of the surgical scar and preventing complications and recurrence. In our cases, the patients did not develop raised scar formation during healing. The surgical site remained soft and smooth and our patients continue to possess full ROM in their treated hand. Additionally, there has been no recurrence in the area of the treated digit and palm at short-term follow-up.

Both patients described in the present report were diabetic. Although we have observed similar results in nondiabetic patients with Dupuytren's disease, it is possible that the effect of nitropaste was more pronounced in these patients because their disease affects the peripheral microcirculation.

These observations suggest that the etiology of Dupuytren's disease initially involves local ischemia, which subsequently results in scar formation in an abnormal distribution. Postoperative topical nitroglycerin may improve the postoperative course by preventing local ischemia, thereby preventing the pathological scarring that underlies the disease. It is possible that continued use may reduce rates of recurrence. Because the present case report was not a formal study, and especially in light of the high variability in the course and postoperative recurrence rates of Dupuytren's disease, these preliminary results should be interpreted with caution. Further study is needed to evaluate the short- and long-term effect of topical nitroglycerin on scarring and disease recurrence.

\section{REFERENCES}

1. McFarlane RM. On the origin and spread of Dupuytren's disease. J Hand Surg Am 2002;27:385-90.

2. Gosset J. Surgical treatment of Dupuytren's disease (MacIndoe's technique). Sem Hop 1951;27:2330-3.

3. Bayat A, McGrouther DA. Management of Dupuytren's disease clear advice for an elusive condition. Ann R Coll Surg Engl 2006;88:3-8.

4. Au-Yong IT, Wildin CJ, Dias JJ, Page RE. A review of common practice in Dupuytren surgery. Tech Hand Up Extrem Surg 2005;9:178-87.

5. Bulstrode NW, Jemec B, Smith PJ. The complications of Dupuytren's contracture surgery. J Hand Surg Am 2005;30:1021-5.

6. Maravic M, Landais P. Dupuytren's disease in France - 1831 to 2001 - from description to economic burden. J Hand Surg Br 2005;30:484-7.

7. Skoff HD. The surgical treatment of Dupuytren's contracture: A synthesis of techniques. Plast Reconstr Surg 2004;113:540-4.

8. Foucher G, Medina J, Navarro R. Percutaneous needle aponeurotomy: Complications and results. J Hand Surg Br 2003;28:427-31.

9. Hurst LC, Badalamente MA, Hentz VR, et al. Injectable collagenase Clostridium histolyticum for Dupuytren's contracture. N Engl J Med 2009;361:968-79.

10. Osadnik R, Redeker J, Kraemer R, Vogt PM, Knobloch K. Microcirculatory effects of topical glyceryl trinitrate on the Achilles tendon microcirculation in patients with previous Achilles tendon rupture. Knee Surg Sports Traumatol Arthrosc 2010;18:977-81.

11. Knobloch K, Hufner T. [Conservative treatment of Achilles tendinopathy.] Unfallchirurg 2010;113:705-11.

12. Mullins PA. Postsurgical rehabilitation of Dupuytren's disease. Hand Clin 1999;15:167-74, viii.

13. Hueston JT, Murrell GA. Cell-controlling factors in Dupuytren's contracture. Ann Chir Main Memb Super 1990;9:135-7.

14. Murrell GA. The role of the fibroblast in Dupuytren's contracture. Hand Clin 1991;7:669-80.

15. Murrell GA. An insight into Dupuytren's contracture. Ann R Coll Surg Engl 1992;74:156-60.

16. Madden JW, Carlson EC, Hines J. Presence of modified fibroblasts in ischemic contracture of the intrinsic musculature of the hand. Surg Gynecol Obstet 1975;140:509-16.

17. McCallum SD, Paoloni JA, Murrell GA. Five-year prospective comparison study of topical glyceryl trinitrate treatment of chronic lateral epicondylosis at the elbow. Br J Sports Med 2011;45:416-20.

18. Puche JJ, Garcia-Coret MJ, Villalba FL, Ali-Mahmoud I, Roig JV. [Local treatment of a chronic anal fissure with diltiazem vs. nitroglycerin. A comparative study.] Cir Esp 87:224-30.

19. Sun Y, Weber KT. Infarct scar: A dynamic tissue. Cardiovasc Res 2000;46:250-6.

20. Knobloch K, Thermann H. [Achilles tendinopathy - modern evidence-based recommendations.] MMW Fortschritte der Medizin. $2008 ; 150: 46-9$. 